\title{
Call for Special Issue Papers: Redefining Resilience and Equity in the Time of Climate Change
}

\author{
All manuscripts should be submitted for consideration: February 28, 2021 \\ Guest Editors: Jalonne L. White-Newsome, PhD; The Kresge Foundation, \\ Senior Program Officer Troy, Michigan, USA \\ Tony Reames, PhD; The University of Michigan, Assistant Professor, Environment \\ and Sustainability, Ann Arbor, Michigan, USA
}

The special issue will explore the innovation occurring in communities across the United States and abroad to address the root causes of climate injustice and fortify community resilience. Resilience can be defined in many ways, but is generally defined as the ability to bounce back into shape or to adapt to conditions despite adversity, trauma, or other threats. Being resilient is rewarded, but low-income communities and communities of color have proven to be beyond resilient. This reality of survival resilience is neither just nor sustainable.

Climate change has exacerbated flooding, brought forward extreme temperatures, and spurred more wildfires. With no substantial national climate policy in place, the use of dirty energy sources like coal, oil, and hydrofracking continue to dominate, delaying progress toward wider use of cleaner energy technologies. Inherently, the lack of climate resilience that is baked into our institutional practices, policies, and programming, coupled with racism keeps certain communities at risk. How do we achieve real climate resiliency in equity in a racially charged climate? This special issue will explore these key questions:

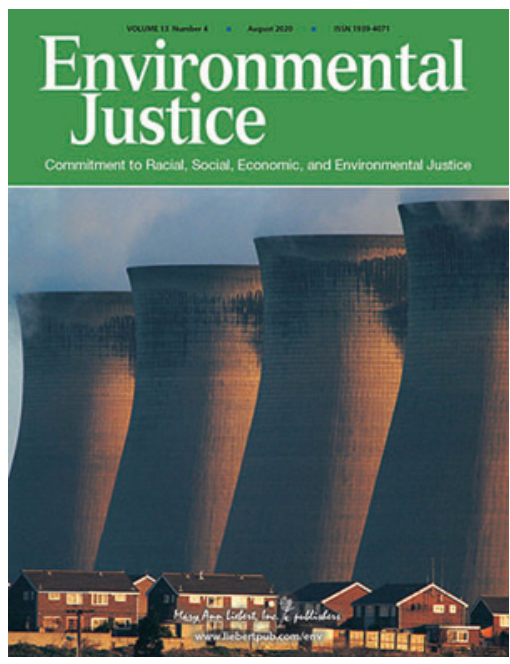

- How do we begin to make the systems and institutions that are not protective or helpful become more climate and energy resilient so there is less of a burden on people to be resilient?

- How is climate and energy resilience being redefined?

- What innovations are occurring as communities handle the concentrated impacts of extreme weather, economic contraction, racial injustice, and a global pandemic?

- What new partnerships are developing that can expand equity in climate and energy resilience?

- What innovations need to be scaled up and/or institutionalized to build equitable community resilience?

- What is being done or how can we begin to systematically track the progress of expanding equity in climate and energy resilience?

We are interested in original research, articles, policy briefs, legal analyses, reviews, and perspectives on these topics and others from a diverse set of stakeholders representing different sectors (academia, government, community, professional societies, national coalitions, etc.).

All manuscripts should be submitted online by February 28, 2021. All submissions will be subject to a rigorous peer review.

\section{Suggested topic areas include, among others:}

- Breaking silos of resilience: work at the energy-water nexus to build local, regional, and state resilience

- Energy injustice

Disparities in residential energy access, generation, consumption, and affordability, focusing on the production and persistence of inequality by race, class, and place

- Tracking our progress on resilience: creating, deploying climate injustice metrics, indicators

Mary Ann Liebert, Inc., publishers, 140 Huguenot Street, New Rochelle, NY 10801, USA. 
- Building the resilience and health of high-risk populations: houseless, those that have mental health issues, the elderly, those with disabilities or who use energy-dependent lifesaving devices, those that do not receive benefits of citizenship, etc.

- Unlikely partnerships that are advancing climate and energy justice between private industry, community, academic partners, and others

- Health impact of planned/unplanned blackouts due to energy reduction tactics and extreme weather (e.g., planning blackouts to reduce wildfires, the effects, impacts...)

- Technological solutions to address climate and energy injustices (renewable energy, energy management systems, extreme heat notification systems)

- Planning and predicting the impacts of climate change to enhance community-level resilience

- Injustice of inaction on climate change-policy, adaptation, mitigation

- The intersections between energy sovereignty, environmental justice, and public health

- Social and environmental determinants of energy poverty and energy resilience

- The potential of energy democracy and climate justice in the United States and other countries

- International struggles for climate and energy justice

Visit Environmental Justice at https://home.liebertpub.com/publications/environmental-justice/259/overview to learn more, read past issues, and view author submission guidelines (https://home.liebertpub.com/ publications/environmental-justice/259/for-authors).

Queries to the editor to propose a topic prior to submission are encouraged. Please contact Dr. Jalonne L. White Newsome (jlwhite-newsome@kresge.org) and Dr. Tony Reames (treames@umich.edu) to initiate your query or for any further details.

Visit the Instructions for Authors:

www.liebertpub.com/env

Submit your paper for peer review online:

https://mc.manuscriptcentral.com/env 